\title{
Walter Benjamin e as Passagens: uma narratividade poética do histórico
}

Davidson de Oliveira Diniz

FALE / UFMG

Resumo: $\mathrm{O}$ artigo propõe-se a refletir o vínculo entre método de análise histórica e a narrativa das Passagens, de Walter Benjamin, apresentando como o conceito de estilo desta obra decorre de uma teoria epistemológica enquanto marca autoral.

Palavras-Chave: montagem literária, Passagens, Walter Benjamin.

\section{Preâmbulo}

Da obra das Passagens, de Walter Benjamin, tomaremos o fichário " $\mathrm{N}$ - Teoria do Conhecimento, Teoria do Progresso", este à luz da montagem literária enquanto base para a cristalização da epistemologia benjaminiana. Assim, procuraremos assimilar a busca de Benjamin por uma narratividade poética do histórico, através da qual o autor pretendia exprimir não somente o objeto de sua problematização histórica, mas também a forma literária mediante a qual essa problematização tomaria expressividade metodológica. Intentar-se-á pontuar, com isso, qual o possível vínculo entre o método historiográfico da narrativa benjaminiana e a concepção de estilo, ambos inscritos na obra em questão por meio da montagem literária de imagens dialéticas. Acresce-se que tais aspectos permitirão considerar o vínculo entre a técnica da montagem e a estruturação da temporalidade, configurando, portanto, a noção de estilo em tal escrita, e ressaltando, por fim, estruturação narrativa e domínio escritural sobrescritos na obra das Passagens, dimensões estas onde se manifesta a teoria benjaminiana do conhecimento (Erkenntnistheorie).

Criticando o evolucionismo historicista dominante na filosofia da história e positivismo decimonônicos, Benjamin colocou-se contrário à idéia de um "tempo homogêneo e vazio", bem como à estruturação narrativa linear que acolhia tal temporalidade enquanto domínio escritural.

\section{O que ler, hoje, das Passagens?}


¿Cómo leeríamos hoy todo Benjamin si la promesa del Libro de los Pasajes se hubiera cumplido?

Ahora, en cambio, no hay libro definitivo pero tenemos una masa todavía más viva de materia: a través de ella espiamos a Benjamin, contradiciendo esa vocación por el secreto y el ocultamiento, de la que hablan sus amigos. La obra es un enigma que, al no haberse resuelto en libro, deja abiertas muchas vías que el libro terminado hubiera clausurado definitivamente. En vez de Paris, capital del siglo XIX tenemos El taller de Walter Benjamin, que nos convoca a la arqueología. Pero se trata de una arqueología inversa: en lugar de reconstruir una totalidad perdida a partir de sus restos, debemos trabajar sobre las ruinas de un edificio nunca construido. ${ }^{1}$

Inicialmente, tomemos aqui a apreciação de Beatriz Sarlo a respeito da "inconclusão" de Das Passagen-Werk, de Walter Benjamin. De acordo com a crítica argentina, um dos pontos positivos relativos ao inconcluso trabalho das Passagens está em permitir-nos tomar conhecimento da procura que toca Benjamin em seu ofício de escritor. Antes que impedir acesso à obra, o fato de o projeto ter restado incompleto coloca o leitor em contato com a concepção seminal do pensamento do autor em sua procura estético-metodológica acerca do que seria seu Magnum opus.

À frente de uma obra "inexistente", o leitor do livro das Passagens depara-se com uma espécie de compilação e coleção material: são transcrições e citações recolhidas durante toda uma vida, bem como também ali uma vida vai a se recolher, enfim, um arquivamento de notas seminais a constituir o esboço de plano teórico da almejada obra em que Benjamin trabalhava como tarefa que lhe significaria o sopro mais vívido do espírito. De sorte a mais fortuita, porquanto o destino acidental meio à tarefa benjaminiana, esse leitor depara-se com um texto no qual está sobrescrito, como bem lembra Susan Buck-Morss, "abundantes traços de um trabalho planejado sem chegar propriamente a realizar-se". ${ }^{2}$

Os aspectos característicos dessa peculiar textura escritural presente no livro das Passagens são enfaticamente ressaltados no Arquivo $N$ - "Teoria do conhecimento, Teoria do progresso". Envoltos numa disposição metacrítica acerca do conhecimento perseguido, ali estão acentuados tanto a planta teórica da obra por vir quanto o núcleo epistemológico do pensamento benjaminiano, fulguralmente amalgamados numa colagem material acerca da idealização do projeto em torno das passagens parisienses. 
E é neste âmbito no qual a teoria do conhecimento aloca-se no trabalho das Passagens que Benjamin ocupa-se de uma crítica a teorias míticas da história, atacando, fundamentalmente, o mito do automático progresso histórico e, por conseguinte, teleológico, que fora dominantemente cristalizado pelo historicismo acentuado durante a ascensão das correntes historiográficas européias no século XIX.

$\mathrm{O}$ foco de análise do autor fecha-se, então, num complexo artefato urbano, avaliando, em suas dimensões materiais e simbólicas, não apenas a cidade de Paris, mas também a espacialização do capitalismo e da arte moderna. ${ }^{3}$ É, pois, no alargamento deste horizonte, acerca da espacialização do capitalismo e da arte moderna, onde se dimensiona a problematização histórica do projeto das Passagens. A análise benjaminiana coloca o século XIX em relação com século XX. Para Benjamin, a cidade de Paris cristaliza um cenário cultural altamente esclarecedor do movimento da arte enquanto mercadoria, uma vez que a cidade materializa e irradia o sonho da modernidade, a ilusão da novidade na circulação das mercadorias e da moda.

Diante disso, é revelador o esforço de Benjamin com relação ao trato do problema histórico que deveria tomar configuração a partir da envergadura metodológica de seu projeto. Consciente de que tal questão não seria alcançada por meio de um materialismo histórico vulgar, Benjamin procurou desvincular-se da ortodoxia marxista referente à relação causal entre aspectos da gênese econômica e superestrutura. Benjamin reconsidera, em função disso, a manutenção da doutrina acerca da superestrutura ideológica; diz o autor:

Sobre a doutrina da superestrutura ideológica. A primeira vista, parece que Marx pretendia somente estabelecer uma relação causal entre superestrutura e infra-estrutura. Mas a observação de que as ideologias da superestrutura refletem as condições de maneira falsa e deformada já vai além. A questão é, de fato, a seguinte: se a infra-estrutura determina de certa forma a superestrutura no material do pensamento e da experiência, mas se esta determinação não reduz a um simples reflexo, como ela deve então ser caracterizada, independentemente da questão da causa de seu surgimento? Como sua expressão. A superestrutura é a expressão da infra-estrutura. As condições econômicas, sob as quais a sociedade existe, encontram na superestrutura a sua expressão - exatamente como o estômago estufado de um homem que dorme, embora possa "condicioná-lo" do ponto de vista causal, encontra no conteúdo do sonho não o seu reflexo, mas a sua expressão. $\mathrm{O}$ coletivo expressa primeiramente suas 
condições de vida. Estas encontram no sonho a sua expressão e no despertar a sua interpretação. ${ }^{4}$

Por meio dessas reconsiderações, busca-se, para o estudo das passagens parisienses, uma correlação expressiva entre tais esferas (base e superestrutura), capaz de exprimir a reflexão pretendida com tal projeto. Elabora-se, consequentemente, um pensamento bastante original segundo este tipo de análise através do qual Benjamin caracterizou seu método próprio relativo ao materialismo histórico. A execução do método benjaminiano, portanto, consiste não em manter intacta a doutrina marxista assentada nos preceitos de uma relação meramente causal entre a gênese material de uma formação econômica e seu reflexo na cultura - e sim na correlação expressiva mediante a qual já é possível assimilar a expressão da economia numa determinada representatividade cultural. Neste sentido, pontua Benjamin:

Marx expõe a relação causal entre economia e cultura. O que conta aqui é a relação expressiva. Não se trata de apresentar a gênese econômica da cultura, e sim a expressão da economia na cultura. Em outras palavras, trata-se da tentativa de apreender um processo econômico como fenômeno primevo perceptível, do qual se originam todas as manifestações de vida das passagens (e, igualmente, do século XIX).$^{5}$

O cotejamento das notas transcritas acima permite assimilar já o centro gravitacional relativo à teoria da correlação expressiva a ser alcançada com projeto das Passagens. Benjamin teoriza acerca da distinção entre superestrutura e infra-estrutura, de maneira a recusar a dessimetria vigente na relação causal entre economia e cultura - a exemplo do que, posteriormente, ressurgiria como preâmbulo epistemológico relativo ao ensaio sobre "A obra de arte na época de sua reprodutibilidade técnica". ${ }^{6}$ Pleiteando desse modo a correlação expressiva a inscrever-se enquanto princípio metodológico, é esclarecedor que, para Benjamin, o estatuto da distinção entre superestrutura e base econômica implique uma dessimetria diretamente associada ao evento histórico, tanto quanto à temporalidade que lhe é própria.

Neste sentido, portanto, cristalizam-se a temática e o problema histórico do projeto vindouro de Benjamin, através do qual o autor pretendia apreender a pré-história do século XX nas formas da mercadoria do século XIX. Com efeito, Benjamin procura decifrar nos modos de vida e na formação cultural decimonônicas, aparentemente 
secundárias, perdidas, o agora de sua temporalidade tomando forma no início do século XX. Ciente disto, o editor alemão das Passagens, Rolf Tiedemann, comenta que, buscando a essência da produção capitalista, Benjamin logra captar desta as formas históricas concretas nas quais a formação econômica encontrava sua expressão cultural. ${ }^{7}$

\section{Crítica ao continuum da história}

Nos domínios de que tratamos aqui, o conhecimento existe apenas em lampejos. O texto é trovão que segue ressoando por muito tempo. ${ }^{8}$

Os aspectos relativos ao traço metodológico do materialismo histórico, tal como são apresentados nas Passagens, influenciaram veementemente a concepção de narrativa perseguida por Benjamin através de seu estilo de escrita, a saber, montagem literária, de modo a expressar também por meio desta o conhecimento historiográfico ${ }^{9}$ de seu projeto acerca das passagens parisienses.

Por tudo isso, Benjamin buscava na técnica da montagem um método capaz de justapor fragmentos literários destinados à evocação constelar de imagens dialéticas e cuja manifestação, apreendida conscientemente pelo sujeito histórico de uma determinada temporalidade, permitiria chegar ao abstrato através do concreto. Diríamos, em outras palavras, que a noção de montagem benjaminiana traz em si a evocação da imagem $($ Bild $)$, cuja apreensão já permite atingir o domínio escritural de uma reflexão a partir de uma base material, porém, sem mais fazer com que a sua legibilidade prescinda desta materialidade concreta do objeto histórico.

Mencionada anteriormente, a crítica apresentada com o trabalho das Passagens fundamenta-se num vigoroso ataque ao historicismo e sua estruturação narrativa atinente ao continuum da história. Pontuando a prática de um encadeamento teleológico dos fatos históricos, Benjamin faz uma crítica consubstancial aos modelos de evolução histórica, para daí recusar tanto a idéia de um avanço positivo quanto a crença no devir da humanidade, ambos postulados enquanto prognósticos cientificistas característicos ao historicismo decimonônico. Segundo sua perspectiva materialista da história, esta "é o objeto de uma construção cujo lugar não é o tempo homogêneo e vazio, mas um tempo saturado de 'agoras",. ${ }^{10}$ 
Cabe ressaltar na concepção de temporalidade relativa ao materialismo histórico benjaminiano, portanto, a atinência para o estrito vínculo entre objeto histórico e estruturação narrativa, por meio do qual ambas instâncias são acolhidas, de um só golpe, estilística e metodologicamente, pelo latente fluxo epistemológico decorrente da teoria do conhecimento em torno das Passagens.

O rigor de tal crítica ao historicismo está, portanto, em perceber que, além de uma estruturação teleológica dos eventos históricos, pontuando o continuum sob o qual é estabelecido o falacioso progresso automático, pesam também aspectos relativos à apresentação da história, isto é, a narratividade dos fatos, a partir da qual o "tempo homogêneo e vazio do progresso" perpetua seu status quo. ${ }^{11}$ As palavras de Benjamin, a seguir transcritas, chamam a refletir acerca do problema em questão:

O materialista histórico não aspira a uma apresentação homogênea nem tampouco contínua da história. Do fato de a superestrutura reagir sobre a infra-estrutura resulta que não existe uma história homogênea, por exemplo, a história da economia, nem tampouco existe história da literatura ou do direito. Por outro lado, uma vez que as diferentes épocas do passado são tocadas pelo presente do historiador em graus diversos (sendo muitas vezes o passado mais recente nem sequer tocado pelo presente; "este não lhe faz justiça"), uma continuidade histórica é inviável. ${ }^{12}$

Conforme Benjamin postula em sua apresentação do materialismo histórico a despeito do historicismo, o qual, segundo o autor, pregava o método da empatia (isto é, indiferença pela atualidade como princípio de conhecimento dos eventos históricos já pretéritos), ${ }^{13}$ um determinado fragmento do passado só é passível de ser tocado pela atualidade uma vez que, entre tais dimensões, atualidade e passado, não haja mais qualquer continuidade. ${ }^{14}$ Eis, portanto, a razão pela qual a apresentação materialista da história, mediante a combinação justaposta de imagens relativas à montagem literária, convoca o passado a colocar o presente numa situação crítica, ${ }^{15}$ ou seja, permitindo-lhe tomar também por seu aquele problema ora consorciado ao conhecimento pretendido na volta para o passado.

Curiosamente, a aparente equalização entre o método do historicismo e a apresentação do materialismo histórico benjaminiano é desfeita tão logo seja percebida a gradação através da qual a estruturação teleológica está inscrita no primeiro. Ali, a 
possibilidade de o passado colocar o presente numa situação crítica é nula, pois a continuidade pretendida faz apenas desfiar os acontecimentos entre os dedos, como as contas de um rosário, a título do "era uma vez" do historicismo enquanto epílogo narrativo para a história do progresso, conforme léxico muito caro à pena de Benjamin. Já o materialismo histórico, este rompe com a continuidade do historicismo: a confluência de temporalidades históricas substitui àquela cena em que antes figurava a idéia de progresso, mediante uma montagem cuja edição está impregnada pela saturação de "agoras" e faz explodir a continuidade da história linearmente transcrita.

Manifestando-se contrariamente à visão do progresso em "uma cadeia de acontecimentos", propõe Benjamin, na nona das teses, que a imagem da história configura um acúmulo de catástrofes cujas ruínas estão dispersas “a nossos pés". ${ }^{16}$

\section{Aniquilamento do progresso}

Redimensionemos, pois, nossa reflexão avaliando também o conceito de progresso, melhor dito, a inscrição deste na disposição metodológica referente ao trabalho das Passagens. A rigor, delinearemos margem para discutir como a técnica da montagem literária apresenta-se como recurso escritural disseminado pela metodologia que perpassa o livro todo. Compreendida à luz das disposições benjaminianas em torno da teoria do progresso, é nossa intenção observar como a técnica da montagem literária, para mais, torna possível uma temporalidade múltipla e, porquanto, transversal à linearidade temporal historicista, a qual Benjamin pretendia aniquilar colocando-se ao encontro de uma confluência entre diversas dimensões temporais presentes em um tempo histórico saturado de "agoras".

A "teoria do progresso" no pensamento de Benjamin é, reverso transcrito, digamos, uma tentativa de aniquilar a idéia de progresso. Aniquilado o progresso, então, não deve mais haver continuidade em sucessão temporal, e sim interferência de uma ação que atualiza a experiência do evento histórico. Por isso impende ser suprimida a idéia de "progresso". Já em seu lugar, portanto, aloca-se o conceito de "atualização". Assim, comenta Benjamin:

Pode-se considerar um dos objetivos metodológicos deste trabalho demonstrar um materialismo histórico que aniquilou em 
si a idéia de progresso. Precisamente aqui o materialismo histórico tem todos os motivos para se diferenciar rigorosamente dos hábitos do pensamento burguês. Seu conceito fundamental não é o progresso, e sim a atualização.$^{17}$

Surpreende que o mérito dessa avaliação, relativa ao materialismo histórico benjaminiano, não esteja meramente restrito ao âmbito da problematização acerca do objeto histórico, ou seja, à dimensão epistemológica implicada na teoria do conhecimento relativa ao projeto das Passagens. Assoma-se a essa mencionada problematização, pois, uma peculiar concepção de narratividade capaz de também expressar o rompimento com a continuidade da história. Em poucas palavras, eis seu ponto crucial: através do entretecimento intradiegético que deve haver entre problematização do objeto histórico e estrutura narrativa específica, capaz de absorver e expressá-los enquanto espessura própria da linguagem, Benjamim procura romper com a racionalidade e linearidade teleológicas, as quais permitem a aderência falaciosa da enteléquia através da qual o progresso toma configuração na apresentação do pensamento historicista.

Poder-se-ia marcar a premissa metacrítica desta teoria do conhecimento na obra benjaminiana desde o texto de sua tese de doutoramento, O Conceito de Crítica de Arte no Romantismo Alemão. Benjamin elabora, neste texto, uma teoria do conhecimento crítico em torno da tradição literária e filosófica originária do pensamento em volta dos primeiros românticos alemães, tais como Schlegel e Novalis. ${ }^{18}$

Segundo a tese benjaminiana relativa à acepção do conceito de crítica de arte pelo romantismo alemão, os primeiros românticos instituem marcos originários de uma peculiar articulação entre crítica e arte. Conforme nota o tradutor brasileiro e também prefaciador desta obra, Márcio Seligmann-Silva, em texto introdutório à referida tese:

Benjamin foi o primeiro a valorizar a teoria romântica da "Reflexão". Este conceito está no centro desta sua tese. Benjamin define a crítica como um "medium-de-reflexão" ("Reflexionsmedium"). Na medida em que ele pôs este conceito no núcleo da sua tese, com todas as suas implicações de crítica ao modelo de teoria do conhecimento monológico, baseado na simples cadeia de causas e efeitos, e, portanto, de crítica também a uma concepção linear tanto do desenvolvimento do conhecimento como também do desenrolar da própria história, ele trouxe à tona um debate - a crítica de um determinado modelo de razão e racionalidade. ${ }^{19}$ 
Partindo do conceito de crítica de arte no romantismo de Jena, Benjamin pensa a obra de arte, portanto, enquanto um "medium de reflexão". Sumariamente, só pode ser considerada obra de arte uma realização estética capaz de desencadear um corpus de reflexão relativo à vontade de conhecimento que a orienta. E uma vez instituído este "processo de reflexão do próprio objeto", enquanto teoria do conhecimento, o conceito de crítica, segundo o romantismo alemão, postula "um experimento da obra de arte através do qual a reflexão desta é despertada e ela é levada à consciência e ao conhecimento de si mesma". ${ }^{20}$

Salvaguardadas as restrições implicadas no deslocamento conceitual, tudo isso é aplicável, sem maiores restrições, à perspectiva de narratividade historiográfica inscrita na obra das Passagens enquanto dimensão epistemológica.

Observamos também ali uma reflexão que se desdobra em volta de si mesma, espécie de meta-texto concebido de modo a correlacionar a teoria do conhecimento com a construção de um estilo capaz de acolhê-la também enquanto domínio escritural. Em outros termos, diríamos: configurando-se a volta do texto para dentro si mesmo, enquanto ato de reflexão referente ao estatuto da linguagem que o acolherá, formula-se então uma narrativa passível de fazer o "medium de reflexão" entre esta e o desejo de conhecimento perseguido durante o traçado da problematização do objeto histórico, passando a assimilar também a dimensão da forma literária capaz de exprimi-lo. E cristaliza-se, desse modo, uma distinta teoria epistemológica assentada no núcleo do projeto das Passagens.

Daí o autor tomar a técnica da montagem literária como dispositivo capaz de veicular à sua escrita historiográfica uma elaboração metodológica já orientada por um ato de auto-reflexão, o qual não pode ser dissociado do plano relativo à tessitura escritural da obra. Tomemos da própria obra das Passagens, portanto, uma sentença afim com este propósito:

Método deste trabalho: montagem literária. Não tenho nada a dizer. Somente a mostrar. Não surrupiarei coisas valiosas, nem me apropriarei de formulações espirituosas. Porém, os farrapos, os resíduos: não quero inventariá-los, e sim fazer-lhes justiça da única maneira possível: utilizando-os. ${ }^{21}$

Entrelaçando teoria do conhecimento com busca estética de uma pretendida estilização literária, Benjamin problematiza o estatuto próprio à metacrítica acerca da 
obra, sem que, para isso, lhe pese o distanciamento enquanto escritor que também a trabalha estilisticamente. Neste sentido é que podemos apreender a representação constelar tão presente na textualidade da obra benjaminiana, em cujo domínio epistemológico, diz o autor, "o conhecimento existe apenas em lampejos", pois, prossegue, "o texto é trovão que segue ressoando por muito tempo". ${ }^{22}$

Para mais, diríamos: tal horizonte, a partir do qual o autor persegue extrair estilisticamente o aspecto eterno do material transitório emergindo do texto, configura a cristalização da busca benjaminiana por uma narratividade poética do histórico; busca esta que podemos reter da imagem que deseja conhecimento em lampejos / texto feito trovão. Muito mais que somente apresentar o objeto recuperado por sua problematização histórica, Benjamin quer encontrar, através dessa textualidade sui generis, um fluxo escritural capaz de representar tematicamente, enquanto ato narrativo, o conteúdo de sua análise, bem como assegurar expressividade metodológica também na dimensão estética de seu projeto.

Herdeiro do princípio de montagem na tradição de vanguardas no século $\mathrm{XX}$, tais como o Dadaísmo e o Surrealismo, Benjamin reorienta, porém, o sentido dominante de ruptura no conceito vanguardista de montagem literária, ${ }^{23}$ e a partir daí, conforme Willi Bolle, passa a tomá-lo, principalmente, por tendência de procedimento construtivo. $^{24}$

Transpondo tal princípio para a escrita da história, desde logo, o autor leva a cabo sua crítica à orientação teleológica cristalizada pela historiografia decimonônica, feita em nome da "evolução social" e do devir do processo histórico:

Um problema central do materialismo histórico a ser finalmente considerado: será que a compreensão marxista da história tem que ser necessariamente adquirida ao preço da visibilidade [Anschaulichkeit] da história? Ou: de que maneira seria possível conciliar um incremento da visibilidade com a realização do método marxista? A primeira etapa desse caminho será aplicar à história o princípio da montagem. Isto é: erguer as grandes construções a partir de elementos minúsculos, recortados com clareza e precisão. E, mesmo, descobrir na análise do pequeno momento individual o cristal do acontecimento total. Portanto, romper com o naturalismo histórico vulgar. Apreender a construção da história como tal na estrutura do comentário. Resíduos da história. ${ }^{25}$ 
A despeito da narrativa cumulativa e complacentemente configurada pela apresentação relativa ao historicismo, portanto, Benjamin sugere a necessidade de investigar os aspectos residuais do processo histórico, pois tais aspectos possibilitam interromper a homogeneidade do vazio linear postulado pela causalidade historicista, na qual se aloca uma aparente coerência dos eventos da história.

Em Benjamin, diferentemente daquilo que ocorre tanto no pensamento hegeliano quanto em Marx, a dialética está não na dinâmica, e sim na imobilidade do evento histórico. É por isso que, em detrimento da linearidade diacrônica do historicismo, o autor aloca em sua escrita e representação da história o sincronismo da interrupção temporal, relativo à "dialética na paralisação" (Dialektik im Stillstand), ou seja, a temporalidade messiânica do choque.

Para Jeanne Marie Gagnebin, estes aspectos presentes no pensamento benjaminiano, acerca da interrupção temporal da história, efetivam uma crítica crucial a dois princípios relativos à trivial idéia de tempo, este enquanto cronologia linear configurando a estrutura narrativa: ora à causalidade histórica, ora à "narrativa falsamente "épica", a qual a autora relaciona com a idéia de continuidade temporal infinita e regular. Neste sentido, escreve Gagnebin:

Lembremos rapidamente que a crítica de Benjamin não diz simplesmente respeito à ideologia do progresso da socialdemocracia, nem somente à erudição cansativa, pretensamente desinteressada do historicismo; por trás dessas duas escritas aparentemente contraditórias da história, Benjamin visa a mesma concepção de "tempo homogêneo e vazio", esse tempo indiferente e infinito que corre, sempre igual a si mesmo, que passa engolfando o sofrimento, o horror, mas também o êxtase e a felicidade. (...) $\mathrm{O}$ instante imobiliza esse desenvolvimento temporal infinito que se esvazia e se esgota e que chamamos rapidamente demais - de história; Benjamin lhe opõe a exigência do presente, que ela seja o exercício árduo da paciência ou o risco da decisão. Se o lembrar do passado não for uma simples enumeração oca, mas a tentativa, sempre retomada, de uma fidelidade àquilo que nele pedia um outro devir (...), então a história que se lembra do passado também é sempre escrita no presente e para o presente. ${ }^{26}$

Isso posto, podemos inferir, a partir da observação de Gagnebin, que há em Benjamin uma identificação da visão do processo histórico a partir da imobilização do processo temporal. E essa visão do processo histórico somente é apreciada a partir da 
"imagem dialética", que, por saturação das diversas temporalidades, cristalizou em si os "agoras" através da paralisação do devir. O materialismo histórico benjaminiano, ainda, nutre a idéia de que o instante autêntico de um presente, arrancado aos eventos, é capaz de interromper o continuum da história, de maneira a explodir seu curso homogêneo e aparentemente coerente. Conforme destacou Benjamin:

Não é que o passado lança luz sobe o presente ou que o presente lança sua luz sobre o passado; mas a imagem é aquilo em que o ocorrido encontra o agora num lampejo, formando uma constelação. Em outras palavras: a imagem é a dialética na imobilidade. Pois, enquanto a relação do presente com o passado é puramente temporal e contínua, a relação do ocorrido com o agora é dialética - não é uma progressão, e sim uma imagem, que salta. - Somente as imagens dialéticas são imagens autênticas (isto é: não-arcaicas), e o lugar onde as encontramos é a linguagem. Despertar. ${ }^{27}$

Por isso a dialética não é, para Benjamin, uma progressão temporal, e sim a imobilidade monadológica de temporalidades históricas insurgentes na instância do presente. Justamente este aspecto da dialética na interrupção é o que permite substituir a noção de progresso pela de "atualização". Dessa forma a autenticidade de uma imagem dialética cristaliza em si as ocorrências destes diversos "agoras", com efeito de sua estrutura monádica.

Há, então, uma confluência de temporalidades a favor de um instante único, o qual toma configuração mediante a disposição da linguagem que o expressa poeticamente no presente, uma vez fazendo escapar-lhe a possibilidade de um anacronismo que, a princípio, o recolheria em confluência temporal. Sumariamente, apenas a imagem dialética na imobilidade é o que assegura o fator "não-arcaico" na relação entre passado e presente, pois:

[o] índice histórico das imagens diz, pois, não apenas que elas pertencem a uma determinada época, mas, sobretudo, que elas só se tornam legíveis numa determinada época. E atingir essa "legibilidade" constitui um determinado ponto crítico específico do movimento em seu interior. Todo presente é determinado por aquelas imagens que lhe são sincrônicas: cada agora é o agora de uma determinada cognoscibilidade. (...) Pois, enquanto a relação do presente com o passado é puramente temporal, a do ocorrido com o agora é dialética - não de natureza temporal, mas imagética. Somente as imagens dialéticas são 
autenticamente históricas, isto é, imagens não-arcaicas. A imagem lida, quer dizer, a imagem no agora da cognoscibilidade, carrega no mais alto grau a marca do momento crítico perigoso, subjacente a toda leitura. ${ }^{28}$

O trecho supracitado permite-nos despertar para a idéia de narratividade benjaminiana, acerca da aliança entre escrita e a concepção de imagem enquanto índice histórico. Neste sentido o estilo das Passagens assinala que "escrever a história significa, portanto, citar a história" - e prossegue - "no conceito de citação está implícito que o objeto histórico em questão seja arrancado do seu contexto". ${ }^{29}$

Benjamin, por tudo isso, atribui a tal escrita da história - cujo princípio esteja em arrancar o objeto do contexto histórico no qual está inserido, para daí apresentá-lo por meio do princípio da montagem - a única forma literária capaz de cristalizar a legibilidade de um presente autêntico em sua teoria do conhecimento. E este momento de autenticidade temporal é, portanto, a oportunidade de efetivação para uma crítica capaz de romper com a causalidade linear e explodir a continuidade do curso da história, momento este apreendido do "choque" mediante a superposição de imagens dialéticas.

\section{Superposição de imagens dialéticas e choque}

Em Fisiognomia da Metrópole moderna, Willi Bolle considera a estrutura de representação da história em Benjamin também a partir dos procedimentos da montagem. O crítico avalia a composição do trabalho das Passagens "como uma montagem de imagens dialéticas". Ocupa-se, então, de uma análise a respeito da articulação das principais técnicas de montagem com a ensaística de Benjamin. Em decorrência disso, Bolle pontua diversos aspectos deste princípio na representação da história por Benjamin, dos quais tomamos em destaque a montagem enquanto forma de choque (Schockhafte Monage) e, também, como superposição (Überlendung). Assim, menciona Bolle:

A superposição de imagens é a mais propícia, entre as técnicas benjaminianas de montagem, para "radiografar" o imaginário coletivo. Em parte, ela se inspira no cinema, em que a "fusão" de duas imagens é obtida pelo esvanecer (fading out) da primeira, da qual surgem, cada vez mais nítidos (fading in), os 
contornos da segunda. Ao lado dessa passagem "suave", existe a "superposição" propriamente dita, que consiste no enclavamento de um plano em cima de outro: por exemplo, a projeção de um transeunte contra um fundo de multidão. Ambas as técnicas são incorporadas à Überlendung benjaminiana, que expressa tanto a simultaneidade de percepções diferentes, quanto um processo cognitivo no limiar entre inconsciente e consciência. ${ }^{30}$

A montagem benjaminiana enquanto forma de choque, eminentemente apreendida pela interpretação de Bolle, tem seus traços em parte na cinematografia. ${ }^{31} \mathrm{~A}$ linguagem cinematográfica não é exatamente o problema de nossa reflexão, todavia, impende colocar em evidência como a montagem literária prescrita por Benjamin assimila a forma de choque em diálogo com os princípios dessa arte.

Conforme a teoria da montagem enquanto linguagem própria do cinema, Serguei Eisenstein e Lev Kulechov (inicialmente o montador dos filmes de Eisenstein) precursores teóricos dessa temática, concebiam a técnica de montagem cinematográfica como um poder criativo do cinema, de modo a tornar as "células" isoladas um conjunto cinemático vivo e capaz de dar significado aos planos justapostos. Em suma, da montagem depende um conflito entre os elementos gráficos dos planos a efetivarem o esplendor de um efeito imagético. ${ }^{32}$

É nesta perspectiva que o princípio de montagem cinematográfica é tomado por Benjamin ao eleger a montagem também como forma de choque, pois, conforme podemos pontuar a partir da teoria de Eisenstein, o que caracteriza a montagem e, consequentemente, sua célula, os fotogramas do plano, é o "conflito entre dois pedaços, um em oposição ao outro", enfim, "montagem é conflito". ${ }^{33}$

Por eleger o efeito de choque da montagem cinematográfica como forma de metamorfoses mais profundas do aparelho perceptivo, Benjamin a prefere em oposição às demais, tal como analisa em seu ensaio sobre "A obra de arte na era de sua reprodutibilidade técnica":

O dadaísmo ainda mantinha, por assim dizer, o choque físico embalado no choque moral; o cinema o libertou desse invólucro. Compare-se a tela em que se projeta o filme com a tela em que se encontra o quadro. Na primeira, a imagem se move, mas na segunda, não. Esta convida o espectador à contemplação; diante dela, ele pode abandonar-se às suas associações. Diante do filme, isso não é mais possível. Mas o espectador percebe uma imagem, ela não é mais a mesma. Ela não pode ser fixada, nem 
como um quadro nem como algo de real. A associação de idéias do espectador é interrompida imediatamente, com a mudança da imagem. Nisso se baseia o efeito de choque provocado pelo cinema, que, como qualquer outro choque, precisa ser interceptado por uma atenção aguda. O cinema é a forma de arte correspondente aos perigos existenciais mais intensos com os quais se confronta o homem contemporâneo. Ele corresponde a metamorfoses profundas do aparelho perceptivo, como as que experimenta o passante, numa escala individual, quando enfrenta o tráfico, e como as experimenta, numa escala histórica, todo aquele que combate a ordem social vigente. ${ }^{34}$

Todos esses aspectos supramencionados são aplicáveis à técnica da montagem literária, apresentada conforme o projeto das Passagens, pois, sem deixar correr demais das mãos o fio específico que nos enlaça à nossa questão, podemos inferir, em seguida, alguns traços estilísticos em vista da representação da história relativa ao pensamento benjaminiano.

A técnica da montagem é utilizada por Benjamin como um processo integrativo das imagens dialéticas, porquanto, paralelamente ao exemplo relativo à montagem do plano imagético como colisão dialética dos fotogramas na acepção ideográfica segundo a cinematografia eisensteiniana, é notável que se inscreva no princípio de choque, operado pela associação benjaminiana das imagens dialéticas, uma "construção que pressupõe "destruição"”. ${ }^{35}$ Acresce que Benjamin não apresenta a imagem pronta, pois sua acepção de escrita é articulada pela técnica da montagem literária de modo a desenvolver ao máximo a arte da citação sem usar aspas.

Opostamente à idéia de imagem pronta, montagem e apresentação benjaminianas configuram, portanto, uma espécie de textualidade fragmentária. Ressalte-se: de tal textualidade advém a narratividade experimentada pelo leitor da obra benjaminiana, o qual é convocado a participar na construção da visibilidade de sua representação histórica de maneira a transformá-la em imagens autênticas de um presente que aparece em manifestações lampejantes. Portanto, esse presente autêntico manifesta-se através da montagem literária, dito de outra maneira, por meio de uma textualidade capaz de colocar o passado em uma relação crítica com o presente. Exatamente em decorrência dessa temporalidade de rasgo transversal é que Benjamin afirma:

A história anterior [Vorgeschichte] e a história posterior [Nachgeschichte] de um fato histórico aparecem nele graças a 
sua apresentação dialética. Além disso: cada fato histórico apresentado dialeticamente se polariza, tornando-se um campo de forças no qual se processa o confronto entre sua história anterior e sua história posterior. Ele se transforma neste campo de forças quando a atualidade penetra nele. E assim o fato histórico se polariza em sua história anterior e posterior sempre de novo, e nunca da mesma maneira. Tal polarização ocorre fora do fato, na própria linha, dividida segundo o corte apolíneo, em que a divisão é feita fora de linha. ${ }^{36}$

Com efeito, a narratividade histórica orientada pela noção de montagem, vinculada à acepção de citação benjaminiana, sugere o choque das imagens dialéticas superposicionadas e que, desde logo, cristaliza em si a atualidade do fato histórico, a partir daí arrancado à falsa continuidade do processo histórico.

Benjamin pretende escrever a história numa acepção de forma literária capaz de assimilar a transitoriedade material dos eventos, cristalizando em si a postulação da verdade mediante uma polarização e flexão da história anterior e posterior de um determinado fato histórico. Procura, com isso, explodir a continuidade histórica também neste fragmentarismo de sua proclamação estética e epistemológica da colagem e da citação, relativas à montagem literária de sua narratividade poética do histórico.

Esta dimensão estética de sua epistemologia, portanto, condensa, também enquanto tessitura narrativa, a crítica feita às teorias míticas da história. Decorre daí o ataque à causalidade historicista decimonônica e, ainda, a recusa pela concepção de tempo "homogêneo e vazio" em cujos domínios é transcrita a apresentação do mito relativo ao progresso automático por detrás da cadeia linear dos eventos históricos, ora apresentados pelas deliberações metodológicas sobrescritas no trabalho das Passagens, ora pelo inconfundível léxico messiânico das Teses em torno do materialismo histórico benjaminiano.

Em consonância com tudo o que veio sendo desfiado durante o fraseado das linhas precedentes, é tempo de desferir as assimilações finais agora que chegamos à vigília despertante a propósito da reflexão pretendida inicialmente: enquanto paradigmática de acolhimento textual, a técnica da montagem literária cristaliza o estilo da narrativa benjaminiana, bem como a sua reflexão metodológica - ambas decorrentes de sua teoria do conhecimento. Impreterivelmente, a técnica escritural das Passagens efetua todo o primado do fragmentário sobre o sistemático, do monádico sobre o linear, de sorte que diversas temáticas são retomadas recorrentemente e, sobrepostas de forma 
abrupta e sem evidente transição, condensam verdadeiros refrões que reaparecem inumeráveis. Afim com o estatuto lampejante, proclamado pelo fulgural texto benjaminiano, o pensamento ali sobrescrito, este é como que estilhaçado para mais de mil partes; já as citações com as quais toma diálogo, estas são então arrancadas de qualquer contexto original para daí serem cotejadas criticamente com o presente.

Por tudo isso a obra configura uma constelação de imagens justapostas: verdadeiro mosaico e também móbile escritural. E essas características são reunidas numa textualidade "lampejante" (blitzhaft) que reclama a adesão do leitor em sua reconstituição, a qual se dá mediante o giro caleidoscópico implicado por uma imagética disseminada por todo o corpo do livro, que, enfim nas mãos desse leitor, parece pedir por um rearranjo dos fragmentos de modo a renascer uma vez mais.

Para que assim ocorresse uma narratividade poética do histórico, Benjamin encontrou na montagem literária estilo e método capazes de acolher textualmente a epistemologia pretendida com o trabalho das Passagens.

\section{Ler as ruínas}

Voltando para citação de Beatriz Sarlo, acerca de como ler o projeto benjaminiano em torno das passagens, questão através da qual aprofundamos na discussão deste artigo, é novamente tentador finalizar o pensamento aqui perseguido mediante outra evocação. Desta vez far-se-á com as palavras de Pierre Missac:

Para Benjamin, na ausência da construção de um edifício que resista à ação dos séculos, construir uma ruína significará se antecipar à catástrofe, agenciar ou "montar" as idéias que estruturam a futura obra em sua nudez conceitual sem transfigurá-la pela escrita. Significa, em suma, descrevê-la em vez de expô-la (darstellen). Em sua forma atual, o PassagenWerk é o produto e o signo dessa intenção. ${ }^{37}$

Enfim, nesta tarefa arqueológica depara-se o leitor das Passagens com a forte imagem benjaminiana da qual reluz o estilo literário para o qual: o conhecimento existe apenas em lampejos. O texto é trovão que seque ressoando por muito tempo. 
Abstract: The paper aims to contemplate the bond between the historical analysis method and the narrative of Passagens, by Walter Benjamin, showing how the concept of style of such work results from an epistemological theory as a mark of the author. Keywords: montage, Passagens, Walter Benjamin.

\section{Referências Bibliográficas}

BENJAMIN, Walter. Magia e Técnica, Arte e Política. Trad. de Sérgio Paulo Rouanet. São Paulo: Brasiliense, 1986. [Obras Escolhidas, vol. I]

BENJAMIN, Walter. O conceito de crítica de arte no romantismo alemão. Trad., Prefácio e Notas de Marcio Seligmann-Silva. São Paulo: Iluminuras, 1993.

BENJAMIN, Walter. Passagens. Trad. de Irene Aron. Belo Horizonte: Editora da UFMG, 2006.

BOLLE, Willi. Fisiognomia da metrópole moderna: representação da história em Walter Benjamin. São Paulo: EDUSP, 2000.

BUCK-MORSS, Susan. Dialética do olhar: Walter Benjamin e o projeto das passagens. Trad. de Ana Luiza Andrade. Belo Horizonte: Editora da UFMG, 2002.

EISENSTEIN, Serguei. O princípio cinematográfico e o ideograma. In: CAMPOS, Haroldo de. Ideograma: lógica, poesia, linguagem. São Paulo: Cultrix, 1986, p. 163185.

GAGNEBIN, Jeanne Marie. História e narração em Walter Benjamin. São Paulo: Perspectiva, 1994.

LÖWY, Michel. Romantismo e messianismo: ensaios sobre Lukács e Benjamin. Trad. de Myrian Verras Baptista e de Magdalena Pizante Baptista. São Paulo: Perspectiva, 1990.

MISSAC, Pierre. Passagem de Walter Benjamin. Trad. de Lílian Escorel. São Paulo: Iluminuras, 1998.

SARLO, Beatriz. Siete ensayos sobre Walter Benjamin. Buenos Aires: Fundo de Cultura Econômica, 2001.

SELIGMANN-SILVA, Márcio. Prefácio. In: BENJAMIN, Walter. O conceito de crítica de arte no romantismo alemão. Trad., Prefácio e Notas de Marcio SeligmannSilva. São Paulo: Iluminuras, 1993, p. 9-14. 
TIEDEMANN. Rolf. Prefácio. In: BENJAMIN, Walter. Passagens. Trad. de Irene Aron. Belo Horizonte: Editora da UFMG, 2006, p. 13-38.

Notas 
1 “Como leríamos hoje todo o Benjamin se a promessa do Livro das Passagens tivesse sido cumprida? Agora, em compensação, não há livro definitivo, todavia, temos uma massa mais viva de matéria: através dela, observamos Benjamin contradizendo essa vocação para o segredo e para o ocultamento, do qual falavam seus amigos. A obra é um enigma que, não tendo desembocado num livro, deixa aberta muitas vias que o livro terminado teria encerrado definitivamente. Em vez de Paris, capital do século XIX, temos $O$ atelier de Walter Benjamin, que nos convoca à arqueologia. Trata-se, porém, de uma arqueologia inversa: em lugar de reconstruir uma totalidade perdida a partir de seus restos, devemos trabalhar sobre as ruínas de um edifício nunca construído" (tradução própria). SARLO. Siete ensayos sobre Walter Benjamin, p. 24.

${ }^{2}$ BUCK-MORSS. Dialética do olhar, p. 76.

${ }^{3}$ Cf. SARLO. Siete ensayos sobre Walter Benjamin, p. 18.

${ }^{4}$ BENJAMIN. Passagens, p. 437.

${ }^{5}$ BENJAMIN. Passagens, p. 502.

${ }^{6}$ "Tendo em vista que a superestrutura se modifica mais lentamente que a base econômica, as mudanças ocorridas nas condições de produção precisaram mais de meio século para refletir-se em todos os setores da cultura. Só hoje podemos indicar de que forma isso se deu. Tais indicações devem por sua vez comportar alguns prognósticos. Mas esses prognósticos não se referem a teses sobre a arte de proletariado depois da tomada do poder, e muito menos na fase da sociedade sem classes, e sim a teses sobre as tendências evolutivas da arte, nas atuais condições produtivas. A dialética dessas tendências não é menos visível na superestrutura que na economia". BENJAMIN. Magia e Técnica, Arte e Politica, p. 165-166.

${ }^{7}$ TIEDEMANN. Prefácio, p. 26.

${ }^{8}$ BENJAMIN. Passagens, p. 499.

${ }^{9}$ Preferencialmente, falaremos aqui de escrita e conhecimento historiográficos numa acepção mais ampla do termo, em detrimento de uma historiografia demasiado específica, por não considerarmos o projeto de Benjamin encerrado nesta terminologia sistemática, a qual nos parece específica à história enquanto disciplina acadêmica, locus epistemológico a que nossa reflexão não busca confiná-lo em vista de sua amplitude epistemológica.

${ }^{10}$ BENJAMIN. Magia e técnica, arte e politica, p. 229.

${ }^{11}$ BENJAMIN. Passagens, p. 517.

${ }^{12}$ BENJAMIN. Passagens, p. 512.

${ }^{13}$ Cf. BENJAMIN. Magia e técnica, arte e politica, p. 225.

${ }^{14}$ Cf. BENJAMIN. Passagens, p. 512.

${ }^{15}$ Cf. BENJAMIN. Passagens, p. 513.

${ }^{16}$ BENJAMIN. Magia e técnica, arte e politica, p. 226.

${ }^{17}$ BENJAMIN. Passagens, p. 502.

${ }^{18}$ Para maiores esclarecimentos acerca da filiação romântica do pensamento de Benjamin, consultar Romantismo $e$ Messianismo, de Michel Löwy, mais especificamente, o capítulo final, "Alarme de incêndio", no qual o autor pontua "as raízes da atitude de Benjamin (...) na tradição romântica"; LÖWY. Romantismo e Messianismo, p. 206.

${ }^{19}$ SELIGMANN-SILVA. Prefácio, p. 10-11.

${ }^{20}$ BENJAMIN. O conceito de crítica de arte no romantismo alemão, p. 74.

${ }^{21}$ BENJAMIN. Passagens, p. 502.

${ }^{22}$ BENJAMIN. Passagens, p. 499.

${ }^{23}$ Segundo Willi Bolle, todas as técnicas de montagem, desenvolvidas pela mídia na modernidade, inscrevem-se na escrita ensaística de Benjamin. E nesta relação entre o princípio da montagem como método de sua escrita, Benjamin pretendeu apresentar como a "historiografia materialista" deveria provar sua "superioridade em relação ao método tradicional", que podemos ler como o historicismo; BOLLE. Fisiognomia da metrópole moderna, p. 89.

${ }^{24}$ BOLLE. Fisiognomia da metrópole moderna, p. 92-93.

${ }^{25}$ BENJAMIN. Passagens, p. 503.

${ }^{26}$ GAGNEBIN. História e narração em Walter Benjamin, p. 111-112.

${ }^{27}$ BENJAMIN. Passagens, p. 504.

${ }^{28}$ BENJAMIN. Passagens, p. 504-505.

${ }^{29}$ BENJAMIN. Passagens, p. 518.

${ }^{30}$ BOLLE. Fisiognomia da metrópole moderna, p. 98-99.

${ }^{31}$ No ensaio sobre "A obra de arte na era de sua reprodutibilidade técnica", podemos observar o autor em suas considerações acerca da perfectibilidade, autenticidade e etc., relativas à refuncionalização social do trabalho artístico meio a "era da obra de arte montável"; BENJAMIN. Magia e técnica, arte e política, p. 176.

${ }^{32}$ Cf.EISENSTEIN. O princípio cinematográfico e o ideograma, p. 168.

${ }^{33}$ EISENSTEIN. O princípio cinematográfico e o ideograma, p. 176-177.

${ }^{34}$ BENJAMIN. Magia e técnica, arte e politica, p. 192. Grifos do autor.

${ }^{35}$ BENJAMIN. Passagens, p. 512.

${ }^{36}$ BENJAMIN. Passagens, p. 512.

${ }^{37}$ MISSAC. Passagem de Walter Benjamin, p. 208. 